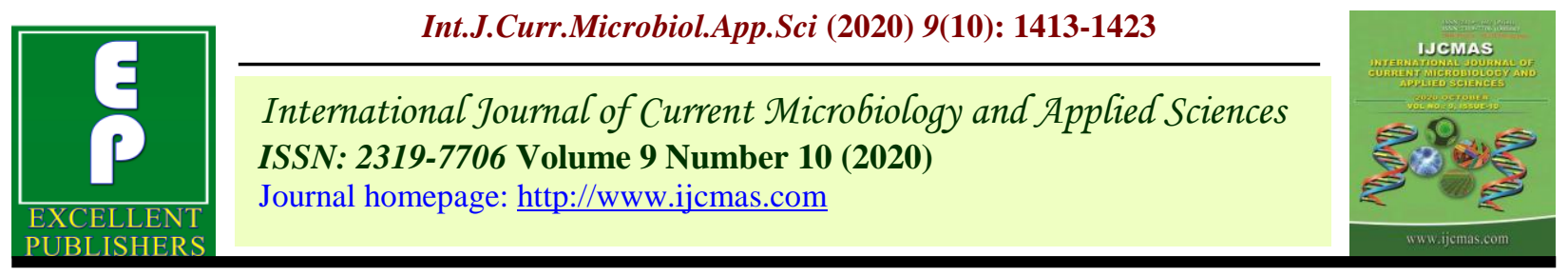

Original Research Article

https://doi.org/10.20546/ijcmas.2020.910.168

\title{
Diversity Analysis of Wheat Genotypes Using SSR Molecular Markers
}

\author{
Megha Singh*, Vaishali and Lalit Kumar \\ Sardar Vallabhbhai Patel University of Agriculture and Technology, Meerut: 250010 \\ College Of Applied Education and Health Sciences, Meerut-250001, India \\ *Corresponding author
}

\begin{tabular}{l} 
K e y w o r d s \\
$\begin{array}{l}\text { Diversity, Genetic } \\
\text { characterisation, } \\
\text { Molecular markers, } \\
\text { Simple Sequence } \\
\text { Repeats (SSR), } \\
\text { Similarity and } \\
\text { variability }\end{array}$ \\
\hline Article Info \\
\hline $\begin{array}{l}\text { Accepted: } \\
\text { 12 September } 2020 \\
\text { Available Online: } \\
\text { 10 October } 2020\end{array}$ \\
\hline
\end{tabular}

\section{A B S T R A C T}

Genetic diversity assessment is an integral part of selecting a highly productive species. Crop improvement is primarily accomplished by continuous infusion of wild relatives, traditional varieties using contemporary breeding techniques, which all require genetic diversity assessment. The present study showed the utility of SSR markers in revealing assessment, genetic variability and molecular characteristics among twenty genotypes of wheat. The studied germplasm were characterized at molecular level using 18 SSR markers. The similarity coefficient value for all the 20 genotypes ranged from 0.69 to 0.89 . The minimum similarity exhibited by genotype DBW16 and PBW226. Whereas, the maximum similarity was shown by genotype K9423 and PBW533. This study has shown the existence of considerable genetic variation among the genotypes considered with may help for further selection and breeding.

\section{Introduction}

Genetic diversity or variation is an inherent plant characteristic that enables it survival in the wild. The importance of plant diversity studies is the morphological and genetic characterization of the germplasm and establishment of a core collection by redundant accession elimination and identification of lines that may be useful for future breeding programme (Govindraj et al., 2010). Genetically informative markers that also provide high through put assays have found use in comparative and structural genome biology as well as molecular breeding. Genetic diversity assessment is an integral part of selecting a highly productive species. Crop improvement is primarily accomplished by continuous infusion of wild relatives, traditional varieties using contemporary breeding techniques, which all require genetic diversity assessment at some level or another (Bhandari et al., 2017). Genetic diversity assessment is very 
important to identify groups with similar genotypes and to conserve, evaluate and utilize the genetic resources. The diversity of the germplasm can be used as a potential basis of genes that lead to improved performance of the superior cultivars. Further, genetic diversity assessment can also be used to determine distinctness and uniqueness of the phenotypes and the genotypes with the objective of protecting the intellectual property rights of the breeder (Nemera et al., 2006).

Molecular markers, due to their stability, costeffectiveness and ease of use provide an immensely popular tool for a variety of applications including genome mapping, gene tagging, genetic diversity, phylogenetic analysis and forensic investigations. In the last three decades a number of molecular marker techniques have been developed and exploited worldwide in different systems. However, only a handful of these techniques, namely RFLPs, RAPDs, AFLPs, ISSRs, SSRs and SNPs have received global acceptance (Grover and Sharma, 2014). A recent revolution in DNA sequencing techniques has taken the discovery and application of molecular markers to high-throughput and ultrahigh-throughput levels. Although, the choice of marker will obviously depend on the targeted use, microsatellites, SNPs and genotyping by sequencing (GBS) largely fulfill most of the user requirements(Grover and Sharma, 2014).

In recent years, the development and use of molecular markers for the detection and exploitation of DNA polymorphism has become one of the most significant developments in the field of molecular genetics and biotechnology for a variety of applications including examination of genetic relationships between individuals, mapping of useful genes, construction of linkage maps, marker assisted selections, backcrosses, population genetics and phylogenetic studies (Kesawat and Das, 2009).

The presence of various types of molecular markers, differences in their principles, methodologies, and applications require careful consideration in choosing one or more of such methods. No molecular markers are available yet that fulfill all requirements needed by researchers. According to the kind of study to be undertaken, one can choose among the variety of molecular techniques, each of which combines at least some desirable properties. Thus, recognizing the enormous potential of DNA markers, it has been adopted the capacity for marker development and marker-assisted selection (MAS) mainly for crop breeding and improvement (Roychowdhary, 2014).

Out of the vast lists of molecular markers, microsatellite or SSR (simple-sequence repeat) markers (Roychowdhury et al., 2012), RAPD (random amplified polymorphic DNA) (Williams et al., 1990), AFLP (amplified fragment length polymorphism) (Vos et al., 1995) RFLP (restriction fragment length polymorphism) (Botstein et al., 1980) are efficiently used in today's research field related to stress tolerance in cereals, floricultural crops, legumes, biodiesel plants, horticultural crops (fruits and vegetables), etc. Amongst these, SSRs and RFLPs are codominant in nature and their genetic map location on crop genome is publicly disclosed; in case of AFLP and RAPD, they produce random amplification and are largely dominant markers in nature (Ram et al., 2007).

PCR based SSR markers are cost-effective, high diversity in crop plants due to their frequently available nature, codominant and greater efficient to others (Temnykh et al., 2000). Compared to RFLPs, microsatellite markers detect a significantly higher degree 
of polymorphism in rice and are especially suitable for evaluating genetic diversity among closely related cultivars (Akagi et al., 1997).Results obtained in genetic diversity studies of crop landraces with SSR markers indicate that more genetic diversity exists in their gene pools. Selection increases the frequency of alleles or allelic combinations with favorable effects at the expense of others, eventually eliminating many of them. Many studies have also reported significantly greater allelic diversity of microsatellite markers than other available molecular markers.

In the fingerprint data, lower polymorphism information contents (PIC-values) may be the result of closely related genotypes (Rahman et $a l .$, 2006). The number of alleles and its PIC values also depends upon the repeat motif and the repeat sequence of the markers. Temnykhet al., (2000) showed that CTT- and AT-rich repeat motifs amplified with higher efficiency leading to greater overall polymorphism. Lastly, the magnitude of similarity matrix value is directly proportional to the varietal genetic/evolutionary distance (Thangadurai et al., 2015)

Salem et al., (2008) reported genetic diversity of the seven wheat varieties at the DNA level using simple sequence repeats (SSR) alleles and morphological characters and revealed that the genotypes differed for morphological characters and SSR markers. The average genetic diversity based on morphological characters was higher than SSR markers. Their results suggested that the classification based on morphological characters and genotypic markers of these wheat genotypes will be useful for wheat breeders to plan crosses for positive traits. Similarly Kumar et al., (2016) showed the potentiality of SSR markers for study of genetic diversity and DNA fingerprinting in fifty four wheat genotypes comprising of 41 Indian origin and
13 exotic genotypes. Arora et al., (2014) assessed the status of genetic diversity among 319 Indian wheat varieties so that they can be used effectively for future breeding practices.

Prasad et al., (2000) examined the utility of a set of 20 wheat SSR markers to detect DNA polymorphism, identify genotypes, and estimate genetic diversity among 55 elite wheat genotypes. They report the range of alleles per locus was 1-13, averaging 7.4, and the PIC range was $0.21-0.90$, averaging 0.71 . Their results demonstrate the utility of microsatellite markers for detecting polymorphism leading to genotype identification and for estimating genetic diversity.

\section{Materials and Methods}

\section{DNA isolation}

For genomic DNA isolation, the standard method of CTAB given by Doyle and Doyle, 1987 was used. CTAB (Cetyl Trimethyl Ammonium Bromide) is a cationic detergent, which solubilized cell membranes and forms a complex with DNA. For isolation of genomic DNA, leaf samples $(0.30 \mathrm{~g}$ of frozen leaves) were ground to fine powder with the help of chilled mortar and pestle using liquid nitrogen and transferred to the eppendorf tube with pre-warmed $2 \mathrm{ml}$ CTAB extraction buffer. Samples were mixed well by inverting the tubes several times. Then samples were incubated for 1 hour in a shaking water bath at $65^{\circ} \mathrm{C}$. An equal volume of Chloroform: Isoamyl alcohol (in the ratio of 24:1) was added to the tubes and mixed gently for 15-20 minutes by inverting the tubes. The eppendorfs were centrifuge at $8,000 \mathrm{rpm}$ for 10 minutes using centrifuge. After centrifugation aqueous phase (supernatant) was transferred to fresh eppendorf and again extracted with equal volume of Chloroform: Isoamyl alcohol $5 \mu \mathrm{l}$ of $(10 \mathrm{mg} / \mathrm{ml})$. RNase 
was added and incubated for 30 minutes. Tubes were again centrifuged at $8000 \mathrm{rpm}$ for $10 \mathrm{~min}$. Aqueous layer was transferred to the fresh eppendorfs and 0.6 volume of chilled Isopropanol was added to the tubes and incubated for $2 \mathrm{hrs}$. After 2 hours at $-20^{\circ} \mathrm{C}$, the eppendorfs tubes were centrifuged at $10,000 \mathrm{rpm}$ for 10 minutes. After centrifugation, this supernatant was discarded and pellet was washed with $70 \%$ ethanol. The air-dried pellet was dissolved in various amounts (100-400 $\mu \mathrm{l})$ of TE buffer according to the size of pellet.

To purify the DNA, the $100 \mu$ l of DNA solution was taken and added 5.0 $\mu$ l of RNase $(10 \mathrm{mg} / \mathrm{ml})$ and incubated at $37^{\circ} \mathrm{C}$ for $1 \mathrm{hr}$. The equal volume of $\mathrm{C}$ : I (24:1) was added to the samples and mixed gently by inverting the tubes. Tubes were spined at 10,000 rpm at $4^{\circ} \mathrm{C}$ for 10 minutes. Aqueous layer was collected in a separate test tube and equal volume of $3 \mathrm{M}$ Sodium Acetate and $300 \mu \mathrm{l}$ of ethanol was added and kept at $-20^{\circ} \mathrm{C}$ for 10 minutes, then centrifuged at $10,000 \mathrm{rpm}$. After centrifugation, the pellet was air dried, dissolved in $100 \mu \mathrm{l}$ of TE buffer and stored at $4^{\circ} \mathrm{C}$ for further use.

\section{Quantitative and qualitative estimation of DNA}

\section{Spectrophotometric analysis of DNA}

The genomic DNA dissolved in TE buffer was taken for quantification by UV absorbance at $260 \mathrm{~nm}$. To measure the concentration, $500 \mu \mathrm{l}$ of DNA sample dissolved in TE buffer was used in Spectrophotometer. Reference was set against TE and then after thorough rinsing of quartz cuvette, the absorbance of the sample was measured at $260 \mathrm{~nm}$ and $280 \mathrm{~nm}$. The ratio of $\mathrm{OD}_{260} / \mathrm{OD}_{280}$ provides an estimate of purity of nucleic acid. Pure preparation of DNA has the ratio between 1.8 and 2.0 and the concentration in $\mu \mathrm{g} / \mathrm{ml}$ was calculated as 1 OD at $260 \mathrm{~nm}$ is equivalent to $50 \mu \mathrm{g} / \mathrm{ml}$ of double stranded DNA.

\section{Agarose gel electrophoresis and gel} documentation of genomic DNA

The quality of DNA was assessed spectrophotometrically and also by gel electrophoresis on $0.8 \%$ agarose gel with known concentrations of uncut DNA as a reference. To test the quality of DNA, samples were run on $0.8 \%$ agarose gel in $1 \mathrm{x}$ TAE buffer and stained with ethidium bromide and checked for contamination by RNA (which usually runs ahead) and the DNA was evaluated by comparing it with a standard undigested DNA sample. Agarose gel electrophoresis of the isolated genomic DNA was performed to carry out quantitative as well as qualitative analysis of DNA. To resolve DNA molecules in the range of 0.7 to $8.5 \mathrm{~kb}$ (expected size of genomic DNA in our samples), $1 \%$ Agarose gel concentration was used. To prepare the gel, the gel tray was set in gel caster (Gel caster for submarine electrophoresis unit, Banglore Genei Pvt. Ltd., India) and comb was set in such a manner so that the teeth were about $1 \mathrm{~mm}$ above the bottom of the gel tray and a complete well was formed to accommodate about $10 \mu \mathrm{l}$ samples. Warm agarose solution was poured gently into the casting tray avoiding formation of air bubbles. Comb carefully removed after the complete setting of gel (after 30-40 min) at room temperature. The gel tray was removed from the gel caster and mounted in the electrophoresis unit (Midi submarine electrophoresis unit, Tarson, India) containing $1 \mathrm{X}$ TBE to cover the gel to a depth of about $1 \mathrm{~mm}$. The $7 \mu \mathrm{l}$ of DNA samples were mixed with $3 \mu 1$ of dye and carefully loaded into the wells of submerged gel using a micro pipette. $1 \mathrm{~Kb}$ ladder of known molecular weight was loaded at one end for reference. The assembly was connected to a power 
supply (Genei PS100 mini model, Bangalore Genei Pvt. Ltd., India) through electrode. The DNA was electrophoresed at $50 \mathrm{~V}$ for $2 \mathrm{hrs}$. After 2 hrs run, the gel was removed from the electrophoresis tank and visualized, photographed and analysed using an Alpha Innotech (Alphaimager) System.

\section{PCR amplification of genomic DNA using SSR primers}

The PCR amplification reagents were procured from Bangalore Genei Pvt. Ltd. DNA amplification reaction with SSR primers were performed in a total of $20 \mu l$ as given in Table 1. All components were mixed gently in $0.2 \mathrm{ml}$ thin walled PCR tubes. A master mix except template DNA was prepared for certain number of tubes to avoid pipetting error. Master mix was mixed by spinning for a short time and distributed in each tube and finally template DNA of all twenty varieties was added to each tube and placed in (Eppendorf Master Cycler Gradient) for amplification. The amplification was performed by using the thermal profile. Annealing temperature for each primer is calculated as $\mathrm{Tm}=(\mathrm{A}+\mathrm{T}) \times 2+(\mathrm{G}+\mathrm{C}) \times 4$. The $\mathrm{Tm}$ used in these experiments was $3-5^{\circ} \mathrm{C}$ lower than the calculated Tm.

\section{Agarose gel electrophoresis of PCR products}

$1.2 \%$ of agarose gel was used to resolve the obtained small size fragments using Midi submarine electrophoresis unit (Tarson, India). Gel was prepared by dissolving appropriate amount of agarose in TAE (1X) buffer. A low range DNA ladder of known molecular weight (100bp) was also loaded at one end. Electrophoresis was done at 50 volts for $1 \mathrm{hrs}$ in $1 \mathrm{X}$ TBE. The gel was then visualized and photographed using Alpha Innotech (Alphaimager) System.

\section{Diversity analysis using SSR markers}

In order to assess the ability of primers to resolve the different varieties the resolving power $(\mathrm{Rp})$ for each primer was calculated following the Prevost and Wilkinson (1999) method as $\mathrm{Rp}=\mathrm{Ib}$ (band information). Resolving Power is calculated as 1-[2 x (0.5p)], $p$ being the proportion of the 20 varieties containing the bands and Gene Diversity is calculated as $1-\sum \mathrm{pi}^{2}$ (Anderson et. al., 1993).Amplification was performed twice and only reproducible amplifications products were included in the data analysis. The bands were scored as present (1) or absent (0) for each DNA sample with all 25 SSR wheat primers. Similarity matrix using the similarity coefficient of Jaccard (1908) was constructed from the whole data. Pair wise distances between DNA accessions were calculated and analysed using the Unweighted Pair Group Method Arithmetic average (UPGMA) (Sneath and Sokal, 1973). Clusters were analysed using the computer program NTSYS-PC, version 2.11s (Rohlf, 2000). In some cases no band were observed, possibly due to insufficient homology between the primer and DNA template. There is also the possibility that this situation might have occurred by failure of the PCR caused by some other region as well.

\section{Results and Discussion}

A total of 18 SSR primers resulted in scorable and reproducible result are considered for the analysis of genetic diversity of wheat genotypes. 18primers generate a total of 118polymorphic bands. The expected gene diversity was calculated for all polymorphic primers and found to be varied from 0.08 with primer 7 to 0.74 with primer 16 with a mean expected diversity of 0.41 (Table 2). The higher mean value of expected gene diversity indicated the informativeness of the primers pairs in detecting genetic diversity. Hence the 
primer pair number 3 , primer 8 , primer 16 and primer 17 seems to more informative as they shown the expected gene diversity value higher than 0.50 and can be used in future studies in the field of taxonomical and genetic resource management.

Resolving power of the 18 SSR primers ranged from a lower value of 0.25 to a higher value of 0.91 with an average of 0.63 resolving power for all polymorphic primers (Table 2). The highest resolving power 0.91 was recorded for the primer 7 . On the other hand the lowest resolving power was 0.25 recorded with the primer 16 (Figure 1). Based on resolving power and ability of primers to differentiate all accessions, the primer pair number 1, primer 2, primer 5, primer 7, primer 9 , primer 10 , primer 11 , primer 12 , primer 13 , primer 14 and primer 18 seems to more informative as they shown the resolving power value higher than 0.63. Thus the significant value of resolving power indicated the ability of primers to resolve the different closely related genotypes of wheat.

\section{Genetic similarity matrix and cluster analysis}

The SSR profile was utilized for estimating pair wise genetic similarities among various entries using Jaccard's coefficient (1908) method. All the polymorphic bands were scored as $0-1$ and the genetic similarity matrix was generated using UPGMA clustering algorithm program by software programme NTSYS-PC version 2.02e. Based on the distance matrix expressed as similarity coefficient, a dendrogram was generated by the UPGMA method. Another dendrogram was also constructed for grouping of minimum variant genotypes of wheat. Similarity coefficient value for all the 20 genotypes ranged from 0.69 to 0.890 .89 (Table 3). The minimum similarity exhibited by genotype DBW16 andPBW226, whereas the maximum similarity was shown by genotype PBW533 with genotype K9423.

\section{Distribution of similarity coefficient}

Distribution of similarity coefficient value for all 20 genotypes ranged from 0.69 to 0.89 (Table 3). The minimum distribution similarity coefficient exhibited between the ranges 0.9-1.0. Whereas the maximum distribution of similarity coefficient was lies between 0.7-0.8.

Table.1 Preparation of PCR reaction mixture

\begin{tabular}{|l|l|l|}
\hline Components & Stock Concentration & $\begin{array}{l}\text { Final } \\
\text { Concentration }\end{array}$ \\
\hline Taq Buffer & $10 \mathrm{x}$ & $\mathbf{1 X}$ \\
\hline $\mathbf{M g C l}_{\mathbf{2}}$ & $25 \mathrm{Mm}$ & $\mathbf{2 . 5 M m}$ \\
\hline dNTPs mix & $10 \mathrm{mM}$ & $\mathbf{1 M m}$ \\
\hline & & \\
\hline Primer $\quad \mathbf{5}$ & $100 \mu \mathrm{M}$ & $\mathbf{1 0 \mu M}$ \\
\hline Primer 3, & $100 \mu \mathrm{M}$ & $\mathbf{1 0} \boldsymbol{\mu M}$ \\
\hline Taq Polymerase & $5 \mathrm{U} / \mu \mathrm{l}$ & $\mathbf{0 . 5} / \boldsymbol{\mu l}$ \\
\hline DNA & $25 \mu \mathrm{g}$ & $\mathbf{5} \boldsymbol{\mu g}$ \\
\hline Water (Milli Pore) & To $\mathbf{m a k e u p ~ f i n a l ~ v o l u m e ~}$ & $\mathbf{2 0} \boldsymbol{\mu l}$ \\
\hline Total & $\mathbf{2 0} \boldsymbol{\mu l}$ & \\
\hline
\end{tabular}


Table.2 Expected gene diversity and resolving power of SSR primer used to amplify 20 wheat genotype

\begin{tabular}{|c|c|c|c|c|c|c|}
\hline S.No. & $\begin{array}{l}\text { Primer } \\
\text { name }\end{array}$ & Sequence & $\begin{array}{l}\text { Total } \\
\text { no. of } \\
\text { bands }\end{array}$ & $\begin{array}{l}\text { No. of } \\
\text { polymor } \\
\text { phic } \\
\text { bands }\end{array}$ & $\begin{array}{l}\text { Expected } \\
\text { gene } \\
\text { diversity/PI } \\
\text { C }\end{array}$ & $\begin{array}{l}\text { Resolving } \\
\text { power }\end{array}$ \\
\hline \multirow[t]{2}{*}{$\mathbf{1}$} & GWM2F & CTGCAAGCCTGTGATCAACT & \multirow[t]{2}{*}{10} & \multirow[t]{2}{*}{10} & \multirow{2}{*}{0.24} & \multirow[t]{2}{*}{0.75} \\
\hline & GWM2R & CATTCTCAAATGATCGAACA & & & & \\
\hline \multirow[t]{2}{*}{2} & GWM5F & GCCAGCTACCTCGATACAACTC & \multirow[t]{2}{*}{3} & \multirow[t]{2}{*}{3} & \multirow[t]{2}{*}{0.30} & \multirow[t]{2}{*}{0.69} \\
\hline & GWM5R & AGAAAGGGCCAGGCTAGTAGT & & & & \\
\hline \multirow[t]{2}{*}{3} & GWM44F & GTTGAGCTTTTCAGTTCGGC & \multirow[t]{2}{*}{2} & \multirow[t]{2}{*}{2} & \multirow[t]{2}{*}{0.50} & \multirow[t]{2}{*}{0.49} \\
\hline & GWM44R & ACTGGCATCCACTGAGCTG & & & & \\
\hline \multirow[t]{2}{*}{4} & GWM46F & GCACGTGAATGGATTGGAC & \multirow{2}{*}{10} & \multirow[t]{2}{*}{10} & \multirow{2}{*}{0.36} & \multirow[t]{2}{*}{0.63} \\
\hline & GWM46R & TGACCCAATAGTGGTGGTCA & & & & \\
\hline \multirow[t]{2}{*}{5} & GWM160F & TTCAATTCAGTCTTGGCTTGG & \multirow[t]{2}{*}{6} & \multirow[t]{2}{*}{6} & \multirow[t]{2}{*}{0.32} & \multirow[t]{2}{*}{0.67} \\
\hline & GWM160R & CTGCAGGAAAAAAAGTACACCC & & & & \\
\hline \multirow[t]{2}{*}{6} & GWM165F & TGCAGTGGTCAGATGTTTCC & \multirow[t]{2}{*}{4} & 4 & 0.48 & 0.51 \\
\hline & GWM165R & СTTTTCTTTCAGATTGCGCC & & & & \\
\hline 7 & GWM186F & GCAGAGCCTGGTTCAAAAAG & 4 & 4 & 0.08 & 0.91 \\
\hline & GWM186R & CGCCTCTAGCGAGAGCTATG & & & & \\
\hline 8 & GWM190F & GTGCTTGCTGAGCTATGAGTC & 2 & 2 & 0.54 & 0.45 \\
\hline & GWM190R & GTGCCACGTGGTACCTTTG & & & & \\
\hline 9 & GWM194F & GATCTGCTCTACTCTCCTCC & 14 & 14 & 0.19 & 0.80 \\
\hline & GWM194R & CGACGCAGAACTTAAACAAG & & & & \\
\hline 10 & GWM219F & GATGAGCGACACCTAGCCTC & 8 & 8 & 0.23 & 0.76 \\
\hline & GWM219R & GGGGTCCGAGTCCACAAC & & & & \\
\hline 11 & GWM265F & TGTTGCGGATGGTCACTATT & 9 & 9 & 0.32 & 0.76 \\
\hline & GWM265R & GAGTACACATTTGGCCTCTGC & & & & \\
\hline 12 & GWM273F & ATTGGACGGACAGATGCTTT & 9 & 9 & 0.11 & 0.88 \\
\hline & GWM273R & AGCAGTGAGGAAGGGGATC & & & & \\
\hline 13 & GWM312F & ATCGCATGATGCACGTAGAG & 2 & 2 & 0.34 & 0.66 \\
\hline & GWM312R & ACATGCATGCCTACCTAATGG & & & & \\
\hline 14 & GWM374F & ATAGTGTGTTGCATGCTGTGTG & 7 & 7 & 0.26 & 0.73 \\
\hline & GWM374R & TCTAATTAGCGTTGGCTGCC & & & & \\
\hline 15 & GWM428F & CGAGGCAGCGAGGATTT & 8 & 8 & 0.48 & 0.51 \\
\hline & GWM428R & TTCTCCACTAGCCCCGC & & & & \\
\hline 16 & GWM437F & GATCAAGACTTTTGTATCTCTC & 6 & 6 & 0.74 & 0.25 \\
\hline & GWM437R & GATGTCCAACAGTTAGCTTA & & & & \\
\hline 17 & GWM458F & AATGGCAATTGGAAGACATAGC & 4 & 4 & 0.68 & 0.31 \\
\hline & GWM458R & TTCGCAATGTTGATTTGGC & & & & \\
\hline 18 & GWM493F & TTCCCATAACTAAAACCGCG & 10 & 10 & 0.26 & 0.73 \\
\hline & GWM493R & GGAACATCATTTCTGGACTTTG & & & & \\
\hline
\end{tabular}


Table.3 Jaccard coefficient of similarity obtained from SSR primers in wheat genotypes

\begin{tabular}{|c|c|c|c|c|c|c|c|c|c|c|c|c|c|c|c|c|c|c|c|c|}
\hline & $\frac{8}{8}$ & $\frac{5}{0}$ & $\frac{\sqrt[6]{2}}{8}$ & $\frac{9}{\frac{9}{2}}$ & $\frac{2}{\frac{2}{2}}$ & $\frac{8}{2}$ & 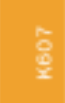 & 愛 & $\frac{8}{8}$ & $\frac{9}{8}$ & 항 & $\frac{\hat{a}}{\frac{6}{x}}$ & $\begin{array}{l}8 \\
\frac{8}{2} \\
\frac{8}{x}\end{array}$ & $\frac{4}{8}$ & 㝵 & $\frac{18}{2}$ & $\frac{\frac{y}{x}}{x}$ & $\frac{3}{3}$ & $\frac{8}{8}$ & $\frac{\overrightarrow{5}}{0}$ \\
\hline Keape & 1.00 & & & & & & & & & & & & & & & & & & & \\
\hline DEW71 & 0.72 & 1.00 & & & & & & & & & & & & & & & & & & \\
\hline PEר:28 & $0.7 \theta$ & 0.69 & 100 & & & & & & & & & & & & & & & & & \\
\hline Mpsopto & 0.78 & 0.82 & 0.75 & 1.00 & & & & & & & & & & & & & & & & \\
\hline HDprses & 0.67 & 0.72 & 0.66 & 0.78 & 100 & & & & & & & & & & & & & & & \\
\hline K12856 & 0.73 & 0.75 & 0.73 & 0.77 & 0.82 & 100 & & & & & & & & & & & & & & \\
\hline KeO7 & 0.77 & 0.73 & 0.77 & 0.71 & 0.73 & $0.9 \theta$ & 1.00 & & & & & & & & & & & & & \\
\hline Pfous73 & 0.71 & 0.83 & 0.76 & 0.75 & 0.67 & 0.75 & 0.78 & 100 & & & & & & & & & & & & \\
\hline PEWW:OO & 0.74 & 0.77 & 0.67 & 0.82 & 0.76 & 0.78 & 0.72 & 0.74 & 1.00 & & & & & & & & & & & \\
\hline DEWA15 & 0.68 & 0.63 & 0.60 & 0.00 & 0.70 & 0.66 & 0.67 & 0.68 & 0.72 & 100 & & & & & & & & & & \\
\hline DEW17 & 0.77 & 0.78 & 0.72 & 0.73 & 0.67 & 0.68 & 0.73 & 0.69 & 0.74 & 0.70 & 1.00 & & & & & & & & & \\
\hline K9507 & 0.77 & 0.81 & 0.66 & 0.80 & 0.74 & 0.78 & 0.70 & 0.74 & 0.81 & 0.70 & 0.79 & 100 & & & & & & & & \\
\hline HDEogs & 0.67 & 0.71 & 0.01 & 0.77 & 0.74 & 0.72 & 0.68 & 0.69 & 0.79 & 0.66 & 0.00 & 0.79 & 1.00 & & & & & & & \\
\hline HDevogs & 0.65 & 0.77 & 0.68 & 0.79 & 0.68 & 0.71 & 0.68 & 0.73 & 0.77 & 0.64 & 0.73 & 0.83 & 0.78 & 1.00 & & & & & & \\
\hline Kes:25 & 0.77 & 0.72 & 0.69 & 0.73 & 0.71 & 0.75 & 0.70 & 0.67 & 0.76 & 0.66 & 0.72 & 0.77 & 0.77 & 0.75 & 100 & & & & & \\
\hline MPS338 & 0.79 & 0.76 & 0.72 & 0.75 & 0.71 & 0.73 & 0.77 & 0.79 & 0.74 & 0.70 & 0.79 & $0.7 \theta$ & 0.76 & 0.77 & 0.83 & 1.00 & & & & \\
\hline HDQESE4 & 0.73 & 0.72 & 0.68 & 0.76 & 0.65 & 0.62 & 0.68 & 0.70 & 0.77 & 0.62 & 0.83 & 0.77 & 0.70 & 0.76 & 0.72 & 0.77 & 100 & & & \\
\hline $\operatorname{kg} 923$ & 0.72 & 0.77 & 0.70 & 0.71 & 0.66 & 0.64 & 0.76 & 0.73 & 0.73 & 0.66 & 0.87 & 0.75 & 0.75 & 0.72 & 0.72 & 0.78 & 0.83 & 1.00 & & \\
\hline PENS539 & 0.75 & 0.80 & 0.73 & 0.74 & 0.70 & $0.0 \theta$ & 0.77 & 0.75 & 0.75 & $0.6 \theta$ & 0.87 & 0.82 & 0.72 & 0.77 & 0.75 & 0.82 & 0.83 & 0.89 & 1.00 & \\
\hline PEw71 & $0.6 \theta$ & 0.74 & 0.69 & 0.77 & 0.66 & 0.63 & 0.66 & $0.6 \theta$ & 0.69 & 0.63 & 0.79 & 0.72 & 0.74 & 0.78 & 0.67 & 0.74 & 0.78 & 0.77 & 0.78 & 100 \\
\hline
\end{tabular}

Table.4 Cluster based grouping of 20 wheat genotypes

\begin{tabular}{|l|c|c|}
\hline GROUP & SUB-GROUP & GENOTYPE \\
\hline I & & K802, PBW226, K607 \\
\hline & II A & DBW71, PBW373 \\
\hline II & MP4010, PBW590, K9107, HD3095, HD3086, \\
\hline & II B & K6525, MP3336 \\
\hline III & & DBW17, K9423, PBW533, HD2864, PBW71 \\
\hline IV & & HD2733 and K1256 \\
\hline V & & DBW16 \\
\hline
\end{tabular}



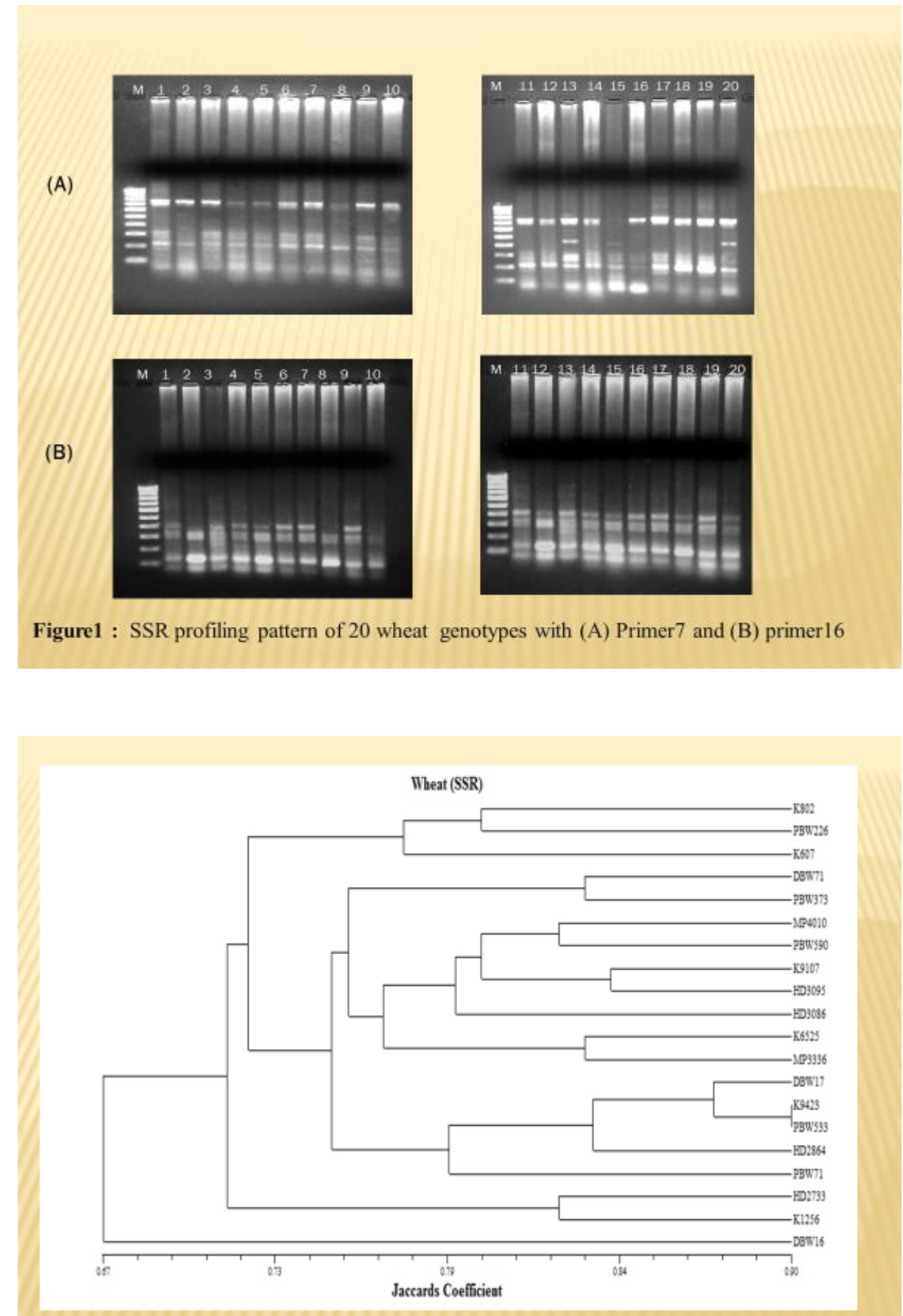

Figure2: Dendrogram showing the cluster based grouping of twenty wheat genotypes. 


\section{Cluster analysis}

Based on the similarity coefficient value, the 20 wheat genotypes were grouped in clusters using Unweighted Paired Group Method of Arithmetic Means (UPGMA). The cluster based dendrogram grouped the 20 wheat genotype into 4 distinct clusters with one independent genotype placed at one end of the cluster at more than $75 \%$ similarity (Figure $1)$.

The main clusters were further subdivided into different subcluster and grouping the sample as per their similarity coefficient value. The major cluster I grouped 3 wheat genotypes viz. K802,PBW226 andK607. The main cluster II was further subdivided into two sub clusters. The subcluster IIa grouped 2 wheat genotypes viz. DBW71 and PBW373. Whereas the subcluster IIb grouped 7 wheat genotypes viz. MP4010, PBW590, K9107, HD3095, HD3086, K6525 and MP3336. The main cluster III grouped 5 wheat genotypes viz. DBW17, K9423, PBW533, HD2864 and PBW71. The main cluster IV is a small cluster and grouped only two wheat genotype viz. HD2733 andK1256. The genotype DBW16 is not grouped with other genotypes and stay separately at one end of the dendrogram (Table 4).

\section{References}

Akagi H., Yokozeki Y., Inagaki A., and Fujimura T. (1997). Highly polymorphic microsatellites of rice consist of AT repeats, and a classification of closely related cultivars with the microsatellite loci. Theor. Appl. Genet. 94. 61-67.

Arora A., Kundu S., Dilbaghi N., Sharma I., and Tiwari R. (2014). Population structure and genetic diversity among Indian wheat varieties using microsatellite (SSR) markers. Aust. J.
Crop Sci.8.1281-1289.

Bhandari H.R., Bhanu A.N., Srivastava K., Singh M.N., Shreya and Hemantaranjan A. (2017). Assessment of genetic diversity in crop plants- an overview. Adv. Plants. Agric. Res. 7. 255

Botstein D., White R.L., Skolnick M. and Davis R.W. (1980). Construction of a genetic linkage map in man using restriction fragment length polymorphisms. Am. J. Hum. Genet.32: 314- 331.

Govindaraj M., Shanmugasundaram P., Sumathi P. and Muthiah A.R. (2010). Simple, rapid and cost effective screening method for drought resistant breeding in pearl millet. Electron. J. Plant Breed. 1. 590- 599.

Grover A. and Sharma P.C. (2014). Development and use of molecular markers: past and present. J. Critica. Rev. in Biotech.36.290-302.

Kesawat, M.S. and Das B.K.(2009). Molecular markers: It's application in crop improvement. J. Crop Sci. Biotech. 12(4): 169-181.

Kumar S., Kumar V., Kumari P., Kirti, Singh A. K. and Singh R. (2016)DNA fingerprinting and genetic diversity studies in wheat genotypes using SSR markers. Journal of Environmental Biology., 319-326.

Nemera G., Labuschagne T.M. and Viljoen C.D.(2006).Genetic diversity analysis in sorghum germplasm as estimated by AFLP, SSR and morpho-agronomical markers, Biodiv. Conserv.15. 32513265.

Prasad M., Varshney R. K., Roy J. K., Balyan H. S. and Gupta P. K. (2000). The use of microsatellites for detecting DNA polymorphism, genotype identification and genetic diversity in wheat. Theoretical and Applied Genetics. 100. 584-592.

Rahman M., Tabassam A., KaziM. and Zafar 
Y. (2006) A step towards wheat genome initiative studies to combat drought in Pakistan using DNA fingerprinting tool. International symposium on strategies for crop improvement against abiotic stresses. September 18-20, Department of Botany University of Agriculture, Faisalabad Pakistan., 15.

Ram S. G., Thiruvengadam V. and Vinod K. K. (2007). Genetic diversity among cultivars, landraces and wild-relatives of rice as revealed by microsatellite markers. J. Appl. Genet. 48(4). 337-345.

Roychowdhary R., Karmakar J., and Dey N. (2012). PCR-compatible genomic DNA isolation from different tissues of rice (Oryza sativa) for SSR fingerprinting. Eurasian J. Bioscience. 6. 85-90.

Roychowhury R., Taoutaou A., Khalid R.K., Mohamed R.A.G. and Jagatpati T. (2014). Crop improvement in the ear of climate change, In: Roychowdhury (eds.), I.K International Publication house Ltd.

Salem K. F. M., El-Zanaty A. M. and Esmail R. M. (2008) Assessing wheat (Triticum aestivum L.) genetic diversity using morphological characters and microsatellite markers. World J Agric Sci., 4:538-544.

Temnykh S., Park W. D., Ayres N., Cartinhour S., Hauck N., Lipovich L., Cho Y. G., Ishii T. and McCouch S. R. (2000). Mapping and genome organization of microsatellite sequences in rice (Oryza sativa L.). Theor. Appl. Genet. 100: 697-712.

Thangadurai D., Kumbar M., Sangeetha J. and Abhishek Mundaragi A. (2015). The molecular assessment of genetic diversity of eggplant cultivars from northern Karnataka in India using Randomly Amplified Polymorphic DNA markers. Scientific Bulletin. Series F. Biotechnologies. 19.76-84.

Vos P., Hogers R., Bleeker M., Reijans M., van de Lee T., Hornes M., Freijters A., Pot J., Peleman J., Kuiper M. and Zabeau M. (1995).AFLP: a new concept for DNA fingerprinting. Nucleic Acids Res. 21. 4407-4414.

Williams J.G.K., Kubelik A.R., Livak K.J., Rafalski J.A., Tingey S.V. (1990). DNA polymorphisms amplified by arbitrary primers are useful as genetic markers. Nucleic Acids Res. 18. 6531-6535.

\section{How to cite this article:}

Megha Singh, Vaishali and Lalit Kumar. 2020. Diversity Analysis of Wheat Genotypes Using SSR Molecular Markers. Int.J.Curr.Microbiol.App.Sci. 9(10): 1413-1423.

doi: https://doi.org/10.20546/ijcmas.2020.910.168 